\title{
The association between plasma fatty acid and cognitive function mediated by inflammation in patients with type 2 diabetes mellitus
}

\author{
Jingyi Shen \\ Capital Medical University \\ Kaifeng Li \\ Capital Medical University \\ Huiyan Yu \\ Capital Medical University \\ Bingjie Ding \\ Capital Medical University Affiliated Beijing Friendship Hospital \\ Rong Xiao \\ Capital Medical University \\ Weiwei Ma ( $\nabla$ weiweima@ccmu.edu.cn ) \\ Capital Medical University https://orcid.org/0000-0002-1792-2760
}

\section{Research}

Keywords: cognitive function, inflammatory cytokines, plasma fatty acids, type 2 diabetes mellitus, mediation model

Posted Date: November 29th, 2021

DOI: https://doi.org/10.21203/rs.3.rs-577863/v3

License: (c) (1) This work is licensed under a Creative Commons Attribution 4.0 International License. Read Full License 


\section{Abstract}

In this study, we evaluated the cognitive function of 372 Chinese patients (214 males and 158 females; the average age was $57.09 \pm 9.00$ years) with type 2 diabetes mellitus (T2DM) by using the mini-mental state examination (MMSE) and the Montreal cognitive assessment (MoCA), with Plasma fatty acids measured by gas chromatography analysis and inflammatory cytokines determined by immune turbidimetric analysis and enzyme-linked immunosorbent assay (ELISA) to investigate whether there was a correlation between the plasma fatty acids, plasma inflammatory cytokine levels and cognitive test scores in Chinese patients with T2DM. We found the increasing of body mass index (BMI) might lead to cognitive impairment and induce inflammatory response. Higher saturated fatty acids (SFAs) levels in plasma were linked to cognitive decline, while higher monounsaturated fatty acids (MUFAs) intake might be a protective factor for cognitive function. In addition, most polyunsaturated fatty acids (PUFAs) levels stood out as having increasing trends that were positively correlated to cognitive function scores. In our study, we found higher SFAs led to higher proinflammatory factor levels. Apart from that, MUFAs and stearoylCoA desaturase-18 (SCD-18) were positively related to hypersensitive C-reactive protein (hs-CRP) $(P<0.05 ; P<0.05 ; P<0.05)$. Meanwhile, our result also indicated that the increasing of $\mathrm{C} 18: 0$ might reduce MoCA language skill scores by regulating plasma IL-10 levels. Plasma fatty acids could improve or damage cognitive function by regulating IL-10, which suggested plasma fatty acids could be evaluated as a potential indicator of cognitive function decline in T2DM.

\section{Introduction}

Diabetes mellitus, exhibited an important influence on the central nervous system, is a group of metabolic diseases in which a person has a high blood glucose level over a prolonged period. According to the report of the International Diabetes Mellitus (IDF) (Mellitus) \there were 463 million living with diabetes in 2017, and the number was predicted to rise to 700 million in 2045, which confirmed that diabetes is one of the largest global health emergencies. The situation is more serious in China. From 2015 to 2017, a nationally representative cross-sectional survey in mainland China was conducted, which showed that the weighted prevalence of diabetes was $11.2 \%$ (using the WHO criteria)(Li et al., 2020).

The discovery that attention and memory of patients with diabetes were worse than normal individuals date back to 1922 reported by Miles (MILES \& ROOT, 1922). There were a growing number of findings indicated that diabetes was associated with accelerated cognitive decline, mild cognitive impairment ( $\mathrm{MCl}$ ), Alzheimer's disease (AD) and dementia (Biessels, Deary, \& Ryan, 2008; J. Q. Li et al., 2016; Nunley et al., 2015; Rawlings et al., 2014). Cognitive impairment in patients with diabetes was often presented as impaired learning and memory, orientation, execution and language skill (Sink et al., 2015; F. Zheng, Yan, Yang, Zhong, \& Xie, 2018). According to epidemiological research, the risk to develop dementia in diabetes patients was higher than normal individuals (Morris, Vidoni, Honea, \& Burns, 2014; Zhang, Lam, Chu, \& Li, 2018). A cohort study showed that the presence of cognitive decline had a 2.5 to a 3.6 - fold increase of type 2 diabetes mellitus (T2DM) patients compared with patients without diabetes (Nooyens, Baan, Spijkerman, \& Verschuren, 2010). This conclusion was also confirmed in animal experiments that the synaptic plasticity of obese Zucker rats reduced, accompanied with the decline in spatial learning and memory compared with lean Zucker rats.

A number of studies suggested that high fat diet could induce increased obesity (Hammad \& Jones, 2017; Namekawa et al., 2017) and diabetes (Barrière et al., 2018), and dietary fatty acids could regulate inflammatory responses (Duca, Sakar, \& Covasa, 2013; Finucane et al., 2015; Pimentel et al., 2012), alleviating or aggravating cognition (Fan, Zhao, Ding, Xiao, \& Ma, 2019). For instance, long chain saturated fatty acids (LCSFAs), such as palmitic acid (16:0) and stearic acids (18:0), would have adverse effects on glucose metabolism, and increase the risk of T2DM (Mozaffarian, 2014). Saturated fatty acids (SFAs) could activate toll-like receptor (TLR), especially TLR2 and TLR4 (Hwang, Kim, \& Lee, 2016), then activate nuclear factor kappa B (NF-KB), resulting in inflammatory responses (Gérard, 2016). By contrast, monounsaturated fatty acids (MUFAs) and polyunsaturated fatty acids (PUFAs) could reduce the concentration of interleukin-6 (IL-6) and tumor necrosis factor-a (TNF-a), and relived inflammatory reaction (Cao et al., 2008; Duca et al., 2013; Souza et al., 2014). However, the role of n-6 PUFAs plays in was still controversies. Recent studies had clearly showed that inflammation is considered as the contributor to diabetic-induced neurodegeneration and cognitive impairment (Duarte et al., 2020). Moreover, the fatty acid profile in plasma, which reflected short-term effects of diets, could reduce desaturase and elongase enzyme activities, considered as biomarkers for the incident T2DM (Lankinen et al., 2015). Researchers found the higher percentages of linoleic acid biomarkers of total fatty acids, the risk of T2DM lower in a study of patients(Wu et al., 2017). However, the role of inflammation in the progression of diabetes-associated cognitive decline remains unknown in patients with T2DM.

Therefore, we investigated whether there was a correlation between the plasma fatty acids, plasma inflammatory cytokine levels and cognitive test scores in Chinese patients with T2DM.

\section{Materials And Methods}

\section{1 | Participants}

Our cross-sectional study included 372 participants with T2DM, recruited among outpatients from the Department of nutrition Beijing Friendship Hospital, Capital Medical University (Beijing, China). Of all the participants, 214 (57.5\%) were males and 158 (42.5\%) were females: the average age was $57.09 \pm 9.00$ years (26-75 years). The study protocol was approved by the ethics committee of Beijing Friendship Hospital, Capital Medical University (Beijing, China) and was performed according to the ethical guidelines of the latest Declaration of Helsinki. All participants have signed an informed consent and had the right to withdraw from the study at any time for any reason. This research was approved by the Ethics Committee of the Beijing Friendship Hospital, Capital Medical University (Beijing, China) (2015-P2-090-02).

Individuals were excluded if they had: (1) severe heart, lung and kidney dysfunction or malignancy; (2) history of encephalitis, head trauma and other central nervous diseases; (3) any type of definite mental illness; (4) reading, hearing, or vision impairments; (5) losing self-caring ability. 
TADM was diagnosed according to the World Health Organization (WHO) criteria: (1) fasting glucose $\geq 7.0 \mathrm{mmol} / \mathrm{L}$; and/or (2) postprandial blood glucose $\geq 11.1 \mathrm{mmol} / \mathrm{L}$; and/or (3) the subjects have been diagnosed T2DM clinically before.

\section{2 | Cognitive function assessments}

All of the participants completed the Chinese versions of the Mini-Mental State Examination (MMSE) and the Montreal Cognitive Assessment (MoCA) to provide a general cognitive status(Ding et al., 2018; Dong et al., 2013). MMSE scale includes MMSE Orientation (maximum 10 points) $\mathbb{M}$ MMSE Computation

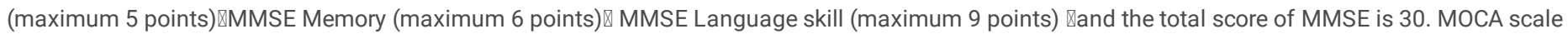
includes MoCA Naming ability (maximum 3 points), MoCA Orientation ability (maximum 6 points), MoCA Delayed recall ability (maximum 5 points), MoCA Abstract thinking ability (maximum 2 points), MoCA Language skill (maximum 3 points), MoCA Visual spatial ability (maximum 5 points) and MoCA Attention ability (maximum 6 points), with a total score of 30 points.

\section{3 | Anthropometric and laboratory measurements}

Height and weight were measured, and body mass index (BMI)was calculated as weight (kg) divided by height (m) squared. Also, we measured waist circumference and calculated waist hip ratio. Following overnight fasting, we used a vacuum tube system (Becton-Dickinson) to take a fasting peripheral blood sample $(4 \mathrm{~mL})$ from the antecubital vein of each participant and centrifuged the sample at $3000 \mathrm{~g}$ for 15 minutes to obtain plasma. And the plasma samples were stored in the dark at $-80^{\circ} \mathrm{C}$. Fasting plasma glucose level was measured by glucose oxidase method (Olympus, Japan). The 2-hour oral glucose tolerance test (OGTT) was performed to assess insulin sensitivity. Next, by using immune turbidimetric analysis (Siemens Healthcare Diagnostics Inc), we measured each participant's plasma hypersensitive C-reactive protein (hs-CRP) and C-reactive protein (CRP). Plasma insulin was measured using a chemiluminescence assay (Beckman Coulter, USA).

\section{4 | Fatty acids analysis}

We used gas chromatography analysis was performed to determine the fatty acid compositions in plasma (ug/ml). The detailed steps were as follows. Firstly, after added $100 \mathrm{ul}$ internal standard in $100 \mathrm{ul}$ plasma samples, $\mathrm{KOH}$ methanol solution $(1 \mathrm{ml} 0.5 \mathrm{~mol} / \mathrm{L})$ was then added and the mixture was shaken in a 60 ${ }^{\circ} \mathrm{C}$ water bath for $10 \mathrm{~min}$. Second, $13 \% \mathrm{BF} 3$-methanol reagent $(3 \mathrm{~mL})$ was added, and kept the hybrid liquid at $60{ }^{\circ} \mathrm{C}$ for 40 min, then cooled it to room temperature. Then the mixture was added in hexane $(1.5 \mathrm{~mL})$ and shaken with vortex for $1 \mathrm{~min}$ immediately. After that, the mixture was added in sodium chloride $(2 \mathrm{~mL})$ in mixture, and centrifuged at $3000 \mathrm{rpm}(15 \mathrm{~min})$, then the upper layer was transferred to a vial for measurement. Finally, fatty acid methyl esters were analyzed using a GC-2010 gas chromatograph (Shimadzu, Japan), equipped with SP-2560 gas chromatographic column (Supelco, USA).

\section{5 | Measurement of plasma inflammatory cytokines}

We measured each participant's inflammatory cytokines (Lipopolysaccharide , IL-1ß, IL-10, NFKBP65 and TNF-a) according to manufacturer instructions using specialized enzyme-linked immunosorbent assay kits (Nanjing Jiancheng Bioengineering Institute, China).

\section{6 | Calculations}

Homeostatic model assessment-IR (HOMA-IR) score was calculated using the formula (fasting insulin $\mu \mathrm{U} / \mathrm{mL} \mathrm{x}$ fasting glucose mmol/L)/22.5 (Matthews et al., 1985). Quantitative sensitivity check index (QUICKI) score was calculated as follows: $1 /$ (log (fasting insulin $\mu \mathrm{U} / \mathrm{mL})+$ log (fasting glucose $\mathrm{mg} / \mathrm{dL}$ ) (Katz et al., 2000). Desaturase activity including stearoyl-CoA desaturase (SCD), delta-5-desaturase (D5D) and delta-6-desaturase (D6D) were estimated using fatty acid product/precursor ratios as following: SCD-16 = C16:1n-7/C16:0, SCD-18 = C18:1n-9/C18:0, D6D = C18:3n-6/C18:2n-6 and D5D = C20:4n-6/C20:3n-6 (K. Li et al., 2016).

\section{7| Statistical analysis}

Data were presented as the mean and standard deviation. Multiple linear regression was used to obtain coefficients between plasma fatty acids, cognition scores, inflammation markers, biochemistry biomarker and diet balance index. Potential confounders including age, gender, energy, BMI, education, smoking habit, alcohol and energy intakes were also included in the model. Multiple linear regression was carried out using $/ m$ function of base R program (version 3.5). Simple mediation model was used to evaluate indirect, direct and total effects between plasma fatty acids, inflammation markers and cognition scores. A thousand bootstrap samples were drew to estimate $\beta$ coefficient indirect, direct and total effects using Mplus version 7.4 (Muthén, Muthén, \& Asparouhov, 2016). Missing values were handled using the full information maximum likelihood implemented within Mplus software. $P<0.05$ was considered to indicate a statistically significant difference.

\section{Results}

\section{1 | The relationship between adiposity indicators, biochemistry biomarkers and inflammation}

Firstly, we measured the relationship between adiposity indicators, biochemistry biomarkers and inflammation after adjusting for age, gender, energy, BMI, education, smoking habit, alcohol and energy intakes. As shown in Table 1, BMI, waist circumference and waist hip ratio were negatively associated with QUICKI $(P<0.01 ; P<0.05)$. AT the same time, BMI and waist circumference both positively correlated with HOMA-IR $(P<0.01)$. In addition, Table 2 indicated that $\mathrm{BMI}$ and waist circumference might be linked to the increase of plasma hs-CRP and CRP level $(P<0.01)$.

\section{2 | The relationship between adiposity indicators and cognitive function score}


We did not find any significant difference in total MoCA score or total MMSE score $(P>0.05)$ (Table 3 and Table 4$)$. However, the increasing of BMI may lead to a drop of the score of Language skill in MoCA $(P<0.05)$ (Table 4).

\section{3 | The relationship between plasma fatty acids, biochemistry biomarkers and inflammation}

In our study, we found different plasma fatty acid had different effects on inflammatory responses and biochemistry biomarkers (Table 5 and Table 6 ). There was positive relationship between C14:0 level and OGTT, OGTT2 and HOMA-IR $(P<0.05)$, while it also had a negative relationship with QUICKI $(P<0.01)$. C16:0 level was positively correlated with HOMA-IR $(P<0.05)$, while it was negatively related to QUICKI $(P<0.05)$. C17:0 level was negatively correlated with insulin $(P<0.05)$. C17:0 level was negatively correlated with 0GTT2 $(P<0.05)$. MUFAs and C18:1n-9 levels were both positively correlated with OGTT and OGTT2 $(P<0.01)$. PUFAs was negatively correlated with HOMA-IR $(P<0.01)$ and positively correlated with QUICKI $(P<0.01)$, as well as n-6 PUFAs and C18:2n-6 levels. In addition, C18:3n-3 level was positively correlated with 0GTT and 0GTT2 $(P<0.05)$, and C22:6n-3 level was positively correlated with QUICKI $(P<0.05)$. C20:4n-6 level was negatively correlated with 0 GTT $(P<0.05)$. SCD-18 was positively correlated with OGTT and OGTT2 $(P<0.01)$. (Table 5$)$ As shown in Table 6, SFAs level was positively correlated with LPS $(P<0.05)$. C16:0 and C18:0 levels were positively correlated with IL-10 and LPS $(P<0.05)$, while C18:0 and C17:0 levels were both negatively correlated with hs-CRP and CRP levels in plasma ( $P<0.05)$. MUFAs, C16:1 and C18:1n-9 levels were positively associated with hs-CRP $(P<0.05)$, but negatively correlated with LPS level. $n-3$ PUFAs level was negatively correlated with TNF-a and hs-CRP levels $(P<0.05)$, and C20:5n-3 level was also negatively correlated with hs-CRP and CRP levels $(P<0.05)$. C18:3n-3, n-6 PUFAs, C18:2n-6 and C18:3n-6 levels were negatively correlated with IL-10 level. C18:3n-3 and C18:2n-6 levels were respectively and negatively correlated with LPS level. SCD16 and SCD-18 both had a positive relationship with hs-CRP level $(P<0.05)$, and a negative relationship with LPS level $(P<0.01)$.

\section{4 | The relationship between plasma fatty acids and cognitive function score}

From Table 7, we found significant difference in total MMSE score and MMSE orientation for SFAs, C16:0 and C18:0 levels ( $P<0.05)$. In our study, C18:0 level was negatively associated with MMSE orientation and delayed recall $(P<0.05)$. Our result also indicated the increasing of MMSE delayed recall scores might result from higher C15:0 and C18:3 n-6 intake and lower D6D. In addition, the level of plasma of SCD-18 higher, total MMSE score higher and accompanied with the orientation ability increasing in participants. However, the result showed greater D5D level was associated with higher MMSE computation scores $(P<0.05)$. As shown in Table 8, SFAs, C16:0 and C18:0 levels were negatively associated with MoCA orientation and language skill, and the growth of C18:0 level in plasma accompanied by a lower MoCA score. In addition, the data exhibited in Table 8 suggested higher MUFAs, C18:1n-9 and SCD-18 levels were associated with increasing of total MoCA and MoCA delayed recall scores $(P<0.05)$. What's more, C18:3n-3 and C20:3n-6 levels were both negatively associated with MoCA naming scores $(P<0.05)$, while PUFAs and C18:2n-6 both had a positive relationship with MoCA orientation scores $(P<0.05)$. C16:1, C18:3n-6, C20:3n-6, SCD-16, D6D levels had a positive relationship with MoCA abstract thinking scores $(P<0.05)$. On the contrast, the relationship between D5D and MoCA abstract thinking scores was negatively $(P<0.05)$. Moreover, C18:2n-6 and SCD-18 levels both were positively associated with MoCA Language skill scores $(P<0.05)$. Finally, higher MoCA attention scores were accompanied by the increasing of C18:3n-6 level and a decreasing of D5D level in plasma $(P<0.05)$.

\section{5 | The relationship between cognitive function score, biochemistry biomarkers and inflammation}

To be verify our hypothesis, we estimated the relationship between cognitive function score, biochemistry biomarkers and inflammation (Table 9 and Table 10). I Elevated levels of IL-1 $\beta$ and NFKBp65 both might cause cognitive function decline, especially orientation, delayed recall and attention function ( $P<0.05)$. Except that, IL-10 might impair language skill. Aside from this, results for MoCA scale supported high insulin level in plasma also led to cognitive function decline $(P<0.05)$.

\section{6 | Summary of mediation models}

All the results above showed that certain plasma fatty acids may be the protective or risk factors of the cognitive function in those living with T2DM in our study, and these effects might be achieved by regulating inflammatory response. Meanwhile, IL-10 was significantly related to plasma fatty acids (C16:0, C18:0, C18:2n-6) and also to MoCA Language skill score. Similarly, HOMA-IR was significantly related to C18:0, C18:2n-6 and MoCA Language skill score. After adjusting for age, gender, energy intakes, BMI, education, smoking and drinking habits, we use Mplus version 7.4 to estimate mediation effect. The result was shown in Table 11 and table 12. Because the total effect was not significant, C16:0 might affect cognitive function by other biological pathway instead of regulating IL-10 levels. However, C18:0 might reduce MoCA Language skill scores by regulating plasma IL-10 levels completely.

\section{Discussion}

Although some previous studies suggested that diabetes-related inflammation may be one of the biological pathways linked fatty acids and cognitive decline (Sharma et al., 2020), definite evidence also need to be verified. Thus, the mediation model was established to examine whether inflammation statistically mediated the relationship between plasma fatty acids and cognition function, which was evaluated by MMSE and MoCA scale.

Previous studies pointed that overweight and obesity were linked to insulin resistance (Kahn \& Flier, 2000), which was frequently associated with inflammation (Parvaresh Rizi et al., 2016). On the contrary, those who were obesity might become insensitive to insulin (McLean et al., 2019). In the present study, we observed similar results. We found a higher HOMA-IR, hs-CRP and CRP levels were related to higher BMI and waist circumference, while QUICKI was negatively related to the markers of obesity. Early studies also revealed waist circumference was significantly related to high prevalence of cognitive dysfunction, which is independent of other related metabolic diseases and lifestyle risk factor, including smoking and drinking (Hou et al., 2019). Based on neuroimaging findings, those who were obesity showed damaged brain structure (brain volume loss and brain atrophy of the grey matter) (Allen et al., 2012; Alosco \& Gunstad, 2014), which indeed lead to cognitive impairment (Gardarsdottir et al., 2018). Similarly, in our study, BMI was negatively correlated with 
MoCA Language skill scores and the increasing of waist circumference may lead to a drop of the score of language skill in MoCA. These findings suggested that inflammation from obesity might cause cognitive decline in T2DM.

Most previous studies indicated high SFAs may be a risk factor of learning and memory ability, while MUFAs and PUFAs had protective effects of age-related cognitive decline (Dohrmann et al., 2019; Solfrizzi et al., 2017). Yu (Yu et al., 2010)found high SFAs diet resulted in obesity in mice and subsequently damaged the function of spatial learning and memory in mice. In a follow-up study, a conclusion was drawn by using structured interviews, which indicated high intake of dietary SFAs could aggravate clinical symptoms in AD patients and increase the risk of AD (Laitinen et al., 2006). Our study gave similar conclusion that SFAs might destroy the orientation and language skill of patients with T2DM. In a prospective population-based study on elder participants with a typical Mediterranean diet, high PUFAs and MUFAs intakes seemed might be protective measure to against age-related cognitive decline (Solfrizzi et al., 2006). $\mathrm{n}-3$ PUFAs could improve cognitive function (Solfrizzi et al., 2011), while the effect on cognitive function of n-6 PUFAs still remained controversial (Kalmijn, Feskens, Launer, \& Kromhout, 1997; MacDonald-Wicks et al., 2019). Some previous studies showed n-6 PUFAs enhanced the tissue inflammatory response (Grimble \& Tappia, 1998), and increased the risk of cognitive impairment (Bigornia, Scott, Harris, \& Tucker, 2018), whereas another study pointed that difference may result from the n-6/n-3 PUFAs ratio in diet (Dong, Xu, Kalueff, \& Song, 2018; Stavrinou et al., 2020). Our result was consistent with previous studies. Higher SFAs levels in plasma were linked to cognitive decline (SFAs, C16:0 and C18:0), and higher MUFAs intake might be a protective factor for cognitive function, except C16:1. In addition, although PUFAs and C18:2n-6 had a positive association with MoCA Orientation, and most PUFAs levels stood out as having increasing trends that were positively correlated to cognitive function scores, the C18:3n-3, C18:3n-6 and C20:3n-6 gave opposite results. However, we didn't find significant difference between cognition function and n-3 PUFAs. This may due to the fact that plasma fatty acids reflect more shortterm intake of dietary fatty acids. In addition, ratio of n-3: n-6 fatty acids might affect the PUFAs metabolism. As reported, the activity of SCD, D5D, D6D was associated with metabolic-related diseases (Bonafini et al., 2020). In this study, similarly, SCD-18 and D5D had positive relationships with cognitive function scores, instead, SCD-16 and D6D showed opposite results. SCD converted a portion of 16:0 into palmitoleic (16:1) and 18:0 into oleic acid (18:1), which might contribute to the moreabundant of MUFAs species. Arachidonic acid (C20:4n-6) and g-linoleate (C18:3n-6) were derived from g-arachidonic acid (C20:3n-6) and linoleate (C18:2n-6) through desaturation (D6D and D5D) and elongation(Kopf et al., 2014). So the activity of D5D and D6D could change the proportion of n-6 PUFAs. Previous studies showed that increasing SCD-1 activity was associated AD(Astarita et al., 2011). Moreover, previous studies indicated higher D5D was associated with better insulin sensitive, while lower D6D activity led to lower risk of insulin resistance(Astarita et al., 2011), which might result in different effect on cognitive function. And the genotype of related genes might affect the metabolic efficiency of PUFAs and desaturase activity, such as FADS1, which encoded D5D(Obukowicz et al., 1999).

Several researches existed that inflammation is involved in the development and/or progression of T2DM (Chawla, Nguyen, \& Goh, 2011; Donath, Marc, Shoelson, \& Steven, 2011). And the inflammatory response could be impacted by diet fatty acids. High fat diet may reduce synaptic plasticity and destroy insulin signaling/glucose homeostasis, which activate the innate immune system, including increased inflammatory cytokines, such as IL-6, IL-1 $\beta$, TNFa (Dutheil, Ota, Wohleb, Rasmussen, \& Duman, 2016). In our study, we found higher SFAs led to higher HOMA-IR and LPS levels, and positive correlation trends had been found between SFAs and NFKBp65, TNF-a. Another study also showed that high SFAs diet led to activated protein kinase, TLR4 and higher HOMA-IR values (Tamer, Ulug, Akyol, \& Nergiz-Unal, 2020). SFAs was reported that contributed to inflammatory response and higher levels of plasma inflammatory factors (e.g., IL-1 $\beta$, IL-6) (Granholm et al., 2008; Hwang et al., 2016). While treating the high fat diet fed mice with palmitoleic acid or oleic acid daily by oral gavage decreased the expression of IL-1 $\beta$ and IL-12 in PPAR-a-knockout mice(Souza et al., 2014). There was another study showed that n-3 PUFAs supplementation could reduce IL-6 and TNF-a production in T2DM (O'Mahoney et al., 2018). In this research, MUFAs, SCD-16 and SCD-18 were positively related to hs-CRP. That might due to the proportion of MUFAs in the diet and diet pattern. In addition, IL-10 has been pointed out to be associated with the occurrence of AD as an anti-inflammatory mediator (Magalhães, Carvalho, Sousa, Caramelli, \& Gomes, 2017). IL-10 could reduce synthesis of proinflammatory and inflammatory responses in the brain as a suppressor so that it could negatively control the immunomodulatory action of IL-1, IL-2, IL-6, IL-8, IL-12 and TNF-a (Ouyang \& O'Garra, 2019), and the effects may have been considerably influenced by single nucleotide polymorphisms (Acuner-Ozbabacan et al., 2014). Interestingly, we found PUFAs were negatively related to IL-10冈which might result from the ratio of $n-3$ : $n-6$ fatty acids. In an animal experiment, researchers found that compared the subjects fed with Mediterranean diet (balanced n-6/n-3 PUFAs ratio), the rats fed with Western diet (high n-6/n-3 PUFAs ratio) showed lower IL-10 levels and accompanied by memory deficits (Haygert et al., 2018). In addition, higher PUFAs led to lower inflammatory cytokines levels, such as hs-CRP, CRP and LPS. This finding provided evidence that the intake of PUFAs could reduce inflammatory response. These increased inflammatory cytokines could induce activation microglia and result in neuroinflammation (Guillemot-Legris \& Muccioli, 2017), accompanied by disrupt neurogenesis and brain structures (Hao, Dey, Yu, \& Stranahan, 2016). For example, in a case-control study, the serum levels of hs-CRP, IL-6 and TNF-a in T2DM subjects with $\mathrm{MCl}$ were significantly higher than type 2 diabetic patients (M. Zheng et al., 2019). Consistently, we showed that higher IL-1 3 , IL-10 and NFKBp65 levels were related to lower cognitive function scores.

In order to verify the effects of fatty acids on inflammation and cognition function, the mediating effect analysis was conducted. There was a significant negative relationship between IL-10 and MoCA language skill in our study. This study found C18:0 could reduce MoCA language skill scores by regulating plasma IL-10 levels. More specifically, through decreasing IL-10 levels of patients with diabetes, higher C18:0 might damage their language skill, which was evaluated by MoCA. In the past few years, some researchers found fatty acids in diet could change IL-10 levels. Supplementation with n-3 PUFA can reduce the inflammatory response in rat, increase levels of IL-10, but decreasing levels of TNF-a, IL-6, IL-1 $\beta$, and IL-17 (Azuma et al., 2018) and higher n-6: $n-3$ fatty acids ratio might reduce IL-10 levels and lead to cognitive impairment (Kahn \& Flier, 2000). Some evidence was given to prove IL-10 could improve spatial cognitive decline in transgenic AD mice (Kiyota et al., 2012). In a cross-sectional analysis, however, higher IL-10 levels were associated with greater odds of $\mathrm{MCl}$ diagnosis (Wennberg et al., 2019). As we previously reported (Preprint)(Shen et al., 2021), though we found the mediating effect of IL-10 on C18:0 and MoCA language skill, more researches were still needed to support this finding.

There were still some limitations in our study. We need expand the sample size and choose different sources of participants instead of limited to hospital patients. Apart from that, erythrocyte membrane fatty acid components of T2DM should be tested to evaluate the dietary fatty acid intake. 


\section{Conclusions}

In conclusion, our study supports the hypothesis that plasma fatty acid can influence cognitive function by regulating inflammation, which suggested that plasma fatty acids can be evaluated as a potential indicator of cognitive function decline.

\section{Declarations}

\section{ACKNOWLEDGEMENTS}

This work was supported by grants from the National Natural Science Foundation of China (N0.81773406).

\section{CONFLICTS OF INTEREST}

The authors declared that they had no conflict of interest.

\section{DATD AVALIABILITY STSTEMENT}

The data that support the findings of this study are available on request from the corresponding author. The data are not publicly available due to privacy or ethical restrictions. The manuscript has been posted to the preprint server Research Square, the link was as follows " DOI:10.21203/rs.3.rs-577863/v1".

\section{ENHICAL APPROVAL}

This research was approved by the Ethics Committee of the Beijing Friendship Hospital, Capital Medical University (Beijing, China) (2015-P2-090-02).

\section{References}

Acuner-Ozbabacan, E. S., Engin, B. H., Guven-Maiorov, E., Kuzu, G., Muratcioglu, S., Baspinar, A., . . Nussinov, R. (2014). The structural network of Interleukin-10 and its implications in inflammation and cancer. BMC Genomics, 15 Suppl 4(Suppl 4), S2. doi:10.1186/1471-2164-15-s4-s2

Allen, P. J., Batra, P., Geiger, B. M., Wommack, T., Gilhooly, C., \& Pothos, E. N. (2012). Rationale and consequences of reclassifying obesity as an addictive disorder: neurobiology, food environment and social policy perspectives. Physiol Behav, 107(1), 126-137. doi:10.1016/j.physbeh.2012.05.005

Alosco, M. L., \& Gunstad, J. (2014). The negative effects of obesity and poor glycemic control on cognitive function: a proposed model for possible mechanisms. Curr Diab Rep, 14(6), 495. doi:10.1007/s11892-014-0495-z

Astarita, G., Jung, K. M., Vasilevko, V., Dipatrizio, N. V., Martin, S. K., Cribbs, D. H., . . Piomelli, D. (2011). Elevated stearoyl-CoA desaturase in brains of patients with Alzheimer's disease. PLoS One, 6(10), e24777. doi:10.1371/journal.pone.0024777

Azuma, M. M., Gomes-Filho, J. E., Ervolino, E., Cardoso, C. B. M., Pipa, C. B., Kawai, T., . . Cintra, L. T. A. (2018). Omega-3 fatty acids reduce inflammation in rat apical periodontitis. J Endod, 44(4), 604-608. doi:10.1016/j.joen.2017.12.008

Barrière, D. A., Noll, C., Roussy, G., Lizotte, F., Kessai, A., Kirby, K., . . Sarret, P. (2018). Combination of high-fat/high-fructose diet and low-dose streptozotocin to model long-term type-2 diabetes complications. Sci Rep, 8(1), 424. doi:10.1038/s41598-017-18896-5

Biessels, G. J., Deary, I. J., \& Ryan, C. M. (2008). Cognition and diabetes: a lifespan perspective. Lancet Neurol, 7(2), 184-190. doi:10.1016/s14744422(08)70021-8

Bigornia, S. J., Scott, T. M., Harris, W. S., \& Tucker, K. L. (2018). Prospective associations of erythrocyte composition and dietary intake of n-3 and n-6 PUFA with measures of cognitive Function. Nutrients, 10(9). doi:10.3390/nu10091253

Bonafini, S., Giontella, A., Tagetti, A., Bresadola, I., Gaudino, R., Cavarzere, P., . . Fava, C. (2020). Fatty acid profile and desaturase activities in 7-10-year-old children attending primary school in verona south district: association between palmitoleic acid, SCD-16, Indices of adiposity, and blood Pressure. Int $J$ Mol Sci, 21(11). doi:10.3390/ijms21113899

Cao, H., Gerhold, K., Mayers, J. R., Wiest, M. M., Watkins, S. M., \& Hotamisligil, G. S. (2008). Identification of a lipokine, a lipid hormone linking adipose tissue to systemic metabolism. Cell, 134(6), 933-944. doi:10.1016/j.cell.2008.07.048

Chawla, A., Nguyen, K. D., \& Goh, Y. P. (2011). Macrophage-mediated inflammation in metabolic disease. Nat Rev Immunol, 11(11), 738-749. doi:10.1038/nri3071

Ding, B., Xiao, R., Ma, W., Zhao, L., Bi, Y., \& Zhang, Y. (2018). The association between macronutrient intake and cognition in individuals aged under 65 in China: a cross-sectional study. BMJ Open, 8(1), e018573. doi:10.1136/bmjopen-2017-018573

Dohrmann, D. D., Putnik, P., Bursać Kovačević, D., Simal-Gandara, J., Lorenzo, J. M., \& Barba, F. J. (2019). Japanese, Mediterranean and Argentinean diets and their potential roles in neurodegenerative diseases. Food Res Int, 120, 464-477. doi:10.1016/j.foodres.2018.10.090

Donath, Marc, Y., Shoelson, \& Steven, E. (2011). Type 2 diabetes as an inflammatory disease. Nature Reviews Immunology. 
Dong, Y., Xu, M., Kalueff, A. V., \& Song, C. (2018). Dietary eicosapentaenoic acid normalizes hippocampal omega-3 and 6 polyunsaturated fatty acid profile, attenuates glial activation and regulates BDNF function in a rodent model of neuroinflammation induced by central interleukin-1 $\beta$ administration. Eur $J$ Nutr, 57(5), 1781-1791. doi:10.1007/s00394-017-1462-7

Dong, Y., Yean Lee, W., Hilal, S., Saini, M., Wong, T. Y., Chen, C. L., . . Ikram, M. K. (2013). Comparison of the Montreal Cognitive Assessment and the MiniMental State Examination in detecting multi-domain mild cognitive impairment in a Chinese sub-sample drawn from a population-based study. Int Psychogeriatr, 25(11), 1831-1838. doi:10.1017/s1041610213001129

Duarte, A. I., Candeias, E., Alves, I. N., Mena, D., Silva, D. F., Machado, N. J., . . Moreira, P. I. (2020). Liraglutide protects against brain Amyloid- $\beta(1-42)$ accumulation in female mice with aarly Alzheimer's disease-like pathology by partially rescuing oxidative/nitrosative stress and inflammation. Int $J$ Mol Sci, 21(5). doi:10.3390/ijms21051746

Duca, F. A., Sakar, Y., \& Covasa, M. (2013). The modulatory role of high fat feeding on gastrointestinal signals in obesity. J Nutr Biochem, 24(10), 1663-1677. doi:10.1016/j.jnutbio.2013.05.005

Dutheil, S., Ota, K. T., Wohleb, E. S., Rasmussen, K., \& Duman, R. S. (2016). High-fat diet induced anxiety and anhedonia: impact on brain homeostasis and inflammation. Neuropsychopharmacology, 41(7), 1874-1887. doi:10.1038/npp.2015.357

Fan, R., Zhao, L., Ding, B. J., Xiao, R., \& Ma, W. W. (2019). The association of blood non-esterified fatty acid, saturated fatty acids, and polyunsaturated fatty acids levels with mild cognitive impairment in Chinese population aged 35-64 years: a cross-sectional study. Nutr Neurosci, 1-13.

doi:10.1080/1028415x.2019.1610606

Finucane, O. M., Lyons, C. L., Murphy, A. M., Reynolds, C. M., Klinger, R., Healy, N. P., . . Roche, H. M. (2015). Monounsaturated fatty acid-enriched high-fat diets impede adipose NLRP3 inflammasome-mediated IL-1 $\beta$ secretion and insulin resistance despite obesity. Diabetes, 64(6), 2116-2128. doi:10.2337/db14-1098

Gardarsdottir, M., Sigurdsson, S., Aspelund, T., Rokita, H., Launer, L. J., Gudnason, V., \& Arnar, D. O. (2018). Atrial fibrillation is associated with decreased total cerebral blood flow and brain perfusion. Europace, 20(8), 1252-1258. doi:10.1093/europace/eux220

Gérard, P. (2016). Gut microbiota and obesity. Cell Mol Life Sci, 73(1), 147-162. doi:10.1007/s00018-015-2061-5

Granholm, A. C., Bimonte-Nelson, H. A., Moore, A. B., Nelson, M. E., Freeman, L. R., \& Sambamurti, K. (2008). Effects of a saturated fat and high cholesterol diet on memory and hippocampal morphology in the middle-aged rat. J Alzheimers Dis, 14(2), 133-145. doi:10.3233/jad-2008-14202

Grimble, R. F., \& Tappia, P. S. (1998). Modulation of pro-inflammatory cytokine biology by unsaturated fatty acids. Z Ernahrungswiss, 37 Supp/ 1, 57-65.

Guillemot-Legris, O., \& Muccioli, G. G. (2017). Obesity-Induced Neuroinflammation: Beyond the Hypothalamus. Trends Neurosci, 40(4), $237-253$.

doi:10.1016/j.tins.2017.02.005

Hammad, S. S., \& Jones, P. J. (2017). Dietary fatty acid composition modulates obesity and interacts with obesity-related genes. Lipids, 52(10), 803-822. doi:10.1007/s11745-017-4291-9

Hao, S., Dey, A., Yu, X., \& Stranahan, A. M. (2016). Dietary obesity reversibly induces synaptic stripping by microglia and impairs hippocampal plasticity. Brain Behav Immun, 51, 230-239. doi:10.1016/j.bbi.2015.08.023

Haygert, P., Roversi, K., Milanesi, L. H., Maurer, L. H., Camponogara, C., Duarte, T., . . Burger, M. E. (2018). Can the dietary fat type facilitate memory impairments in adulthood? A comparative study between Mediterranean and Western-based diet in rats. J Nutr Biochem, 59, 104-113.

doi:10.1016/j.jnutbio.2018.05.015

Hou, Q., Guan, Y., Yu, W., Liu, X., Wu, L., Xiao, M., \& Lü, Y. (2019). Associations between obesity and cognitive impairment in the Chinese elderly: an observational study. Clin Interv Aging, 14, 367-373. doi:10.2147/cia.S192050

Hwang, D. H., Kim, J. A., \& Lee, J. Y. (2016). Mechanisms for the activation of Toll-like receptor 2/4 by saturated fatty acids and inhibition by docosahexaenoic acid. Eur J Pharmacol, 785, 24-35. doi:10.1016/j.ejphar.2016.04.024

Kahn, B. B., \& Flier, J. S. (2000). Obesity and insulin resistance. J Clin Invest, 106(4), 473-481. doi:10.1172/jci10842

Kalmijn, S., Feskens, E. J., Launer, L. J., \& Kromhout, D. (1997). Polyunsaturated fatty acids, antioxidants, and cognitive function in very old men. Am J Epidemiol, 145(1), 33-41. doi:10.1093/oxfordjournals.aje.a009029

Katz, A., Nambi, S. S., Mather, K., Baron, A. D., Follmann, D. A., Sullivan, G., \& Quon, M. J. (2000). Quantitative insulin sensitivity check index: a simple, accurate method for assessing insulin sensitivity in humans. J Clin Endocrinol Metab, 85(7), 2402-2410. doi:10.1210/jcem.85.7.6661

Kiyota, T., Ingraham, K. L., Swan, R. J., Jacobsen, M. T., Andrews, S. J., \& Ikezu, T. (2012). AAV serotype 2/1-mediated gene delivery of anti-inflammatory interleukin-10 enhances neurogenesis and cognitive function in APP+PS1 mice. Gene Ther, 19(7), 724-733. doi:10.1038/gt.2011.126

Kopf, T., Schaefer, H. L., Troetzmueller, M., Koefeler, H., Broenstrup, M., Konovalova, T., \& Schmitz, G. (2014). Influence of fenofibrate treatment on triacylglycerides, diacylglycerides and fatty acids in fructose fed rats. PLoS One, 9(9), e106849. doi:10.1371/journal.pone.0106849

Page $7 / 13$ 
Laitinen, M. H., Ngandu, T., Rovio, S., Helkala, E. L., Uusitalo, U., Viitanen, M., . . Kivipelto, M. (2006). Fat intake at midlife and risk of dementia and Alzheimer's disease: a population-based study. Dement Geriatr Cogn Disord, 22(1), 99-107. doi:10.1159/000093478

Lankinen, M. A., Stančáková, A., Uusitupa, M., Ågren, J., Pihlajamäki, J., Kuusisto, J., . . Laakso, M. (2015). Plasma fatty acids as predictors of glycaemia and type 2 diabetes. Diabetologia, 58(11), 2533-2544. doi:10.1007/s00125-015-3730-5

Li, J. Q., Tan, L., Wang, H. F., Tan, M. S., Tan, L., Xu, W., . . Yu, J. T. (2016). Risk factors for predicting progression from mild cognitive impairment to Alzheimer's disease: a systematic review and meta-analysis of cohort studies. J Neurol Neurosurg Psychiatry, 87(5), 476-484. doi:10.1136/jnnp-2014-310095

Li, K., Brennan, L., McNulty, B. A., Bloomfield, J. F., Duff, D. J., Devlin, N. F., . . Nugent, A. P. (2016). Plasma fatty acid patterns reflect dietary habits and metabolic health: A cross-sectional study. Mol Nutr Food Res, 6O(9), 2043-2052. doi:10.1002/mnfr.201500711

Li, Y., Teng, D., Shi, X., Qin, G., Qin, Y., Quan, H., . . Shan, Z. (2020). Prevalence of diabetes recorded in mainland China using 2018 diagnostic criteria from the American Diabetes Association: national cross sectional study. Bmj, 369, m997. doi:10.1136/bmj.m997

MacDonald-Wicks, L., McEvoy, M., Magennis, E., Schofield, P. W., Patterson, A. J., \& Zacharia, K. (2019). Dietary long-chain fatty acids and cognitive performance in older australian adults. Nutrients, 11(4). doi:10.3390/nu11040711

Magalhães, C. A., Carvalho, M. D. G., Sousa, L. P., Caramelli, P., \& Gomes, K. B. (2017). Alzheimer's disease and cytokine IL-10 gene polymorphisms: is there an association? Arq Neuropsiquiatr, 75(9), 649-656. doi:10.1590/0004-282x20170110

Matthews, D. R., Hosker, J. P., Rudenski, A. S., Naylor, B. A., Treacher, D. F., \& Turner, R. C. (1985). Homeostasis model assessment: insulin resistance and betacell function from fasting plasma glucose and insulin concentrations in man. Diabetologia, 28(7), 412-419. doi:10.1007/bf00280883

McLean, F. H., Campbell, F. M., Langston, R. F., Sergi, D., Resch, C., Grant, C., . . Williams, L. M. (2019). A high-fat diet induces rapid changes in the mouse hypothalamic proteome. Nutr Metab (Lond), 16, 26. doi:10.1186/s12986-019-0352-9

Mellitus, I. D. (Producer). Retrieved from https://www.diabetesatlas.org/en/

MILES, W. R., \& ROOT, H. F. (1922). Psychologic tests applied to diabetic patients. Archives of Internal Medicine, 30(6), 767-777. doi:10.1001/archinte.1922.00110120086003 \%J Archives of Internal Medicine

Morris, J. K., Vidoni, E. D., Honea, R. A., \& Burns, J. M. (2014). Impaired glycemia increases disease progression in mild cognitive impairment. Neurobiol Aging, 35(3), 585-589. doi:10.1016/j.neurobiolaging.2013.09.033

Mozaffarian, D. (2014). Saturated fatty acids and type 2 diabetes: more evidence to re-invent dietary guidelines. Lancet Diabetes Endocrinol, 2(10), 770-772. doi:10.1016/s2213-8587(14)70166-4

Muthén, B. O., Muthén, L. K., \& Asparouhov, T. (2016). Regression and mediation analysis using mplus.

Namekawa, J., Takagi, Y., Wakabayashi, K., Nakamura, Y., Watanabe, A., Nagakubo, D., . . Asai, F. (2017). Effects of high-fat diet and fructose-rich diet on obesity, dyslipidemia and hyperglycemia in the WBN/Kob-Lepr(fa) rat, a new model of type 2 diabetes mellitus. J Vet Med Sci, 79(6), 988-991.

doi:10.1292/jvms.17-0136

Nooyens, A. C., Baan, C. A., Spijkerman, A. M., \& Verschuren, W. M. (2010). Type 2 diabetes and cognitive decline in middle-aged men and women: the Doetinchem Cohort Study. Diabetes Care, 33(9), 1964-1969. doi:10.2337/dc09-2038

Nunley, K. A., Rosano, C., Ryan, C. M., Jennings, J. R., Aizenstein, H. J., Zgibor, J. C., . . Saxton, J. A. (2015). Clinically relevant cognitive impairment in middleaged adults with childhood-onset Type 1 diabetes. Diabetes Care, 38(9), 1768-1776. doi:10.2337/dc15-0041

O'Mahoney, L. L., Matu, J., Price, O. J., Birch, K. M., Ajjan, R. A., Farrar, D., . . Campbell, M. D. (2018). Omega-3 polyunsaturated fatty acids favourably modulate cardiometabolic biomarkers in type 2 diabetes: a meta-analysis and meta-regression of randomized controlled trials. Cardiovasc Diabetol, $17(1), 98$. doi:10.1186/s12933-018-0740-x

Obukowicz, M., Welsch, D., Salsgiver, W., Martin-Berger, C., Chinn, K., Duffin, K., . . Needleman, P. (1999). Novel, selective delta6 or delta5 fatty acid desaturase inhibitors as antiinflammatory agents in mice. Lipids, 34 Suppl, S149. doi:10.1007/bf02562269

Ouyang, W., \& O'Garra, A. (2019). IL-10 family cytokines IL-10 and IL-22: from basic science to clinical translation. Immunity, 50(4), 871-891. doi:10.1016/j.immuni.2019.03.020

Parvaresh Rizi, E., Baig, S., Shabeer, M., Teo, Y., Mok, S. F., Loh, T. P., . . Toh, S. A. (2016). Meal rich in carbohydrate, but not protein or fat, reveals adverse immunometabolic responses associated with obesity. Nutr J, 15(1), 100. doi:10.1186/s12937-016-0219-0

Pimentel, G. D., Lira, F. S., Rosa, J. C., Oliveira, J. L., Losinskas-Hachul, A. C., Souza, G. I., . . Pisani, L. P. (2012). Intake of trans fatty acids during gestation and lactation leads to hypothalamic inflammation via TLR4/NFKBp65 signaling in adult offspring. J Nutr Biochem, 23(3), $265-271$.

doi:10.1016/j.jnutbio.2010.12.003 
Rawlings, A. M., Sharrett, A. R., Schneider, A. L., Coresh, J., Albert, M., Couper, D., . . Selvin, E. (2014). Diabetes in midlife and cognitive change over 20 years: a cohort study. Ann Intern Med, 161(11), 785-793. doi:10.7326/m14-0737

Sharma, G., Parihar, A., Talaiya, T., Dubey, K., Porwal, B., \& Parihar, M. S. (2020). Cognitive impairments in type 2 diabetes, risk factors and preventive strategies. J Basic Clin Physiol Pharmacol, 31(2). doi:10.1515/jbcpp-2019-0105

Shen, J., Li, K., Yu, H., Ding, B., Xiao, R., \& Ma, W. (2021). The association between plasma fatty acid and cognitive function mediated by inflammation in patients with type 2 diabetes. doi:https://doi.org/10.21203/rs.3.rs-577863/v1

Sink, K. M., Divers, J., Whitlow, C. T., Palmer, N. D., Smith, S. C., Xu, J., . . Freedman, B. I. (2015). Cerebral structural changes in diabetic kidney disease: African American-Diabetes Heart Study MIND. Diabetes Care, 38(2), 206-212. doi:10.2337/dc14-1231

Solfrizzi, V., Colacicco, A. M., D'Introno, A., Capurso, C., Torres, F., Rizzo, C., . . Panza, F. (2006). Dietary intake of unsaturated fatty acids and age-related cognitive decline: a 8.5-year follow-up of the Italian Longitudinal Study on Aging. Neurobiol Aging, 27(11), 1694-1704.

doi:10.1016/j.neurobiolaging.2005.09.026

Solfrizzi, V., Custodero, C., Lozupone, M., Imbimbo, B. P., Valiani, V., Agosti, P., . . Panza, F. (2017). Relationships of dietary patterns, foods, and micro- and macronutrients with Alzheimer's disease and late-life cognitive disorders: a systematic review. J Alzheimers Dis, 59(3), 815-849. doi:10.3233/jad-170248

Solfrizzi, V., Frisardi, V., Seripa, D., Logroscino, G., Imbimbo, B. P., D'Onofrio, G., . . Panza, F. (2011). Mediterranean diet in predementia and dementia syndromes. Curr Alzheimer Res, 8(5), 520-542. doi:10.2174/156720511796391809

Souza, C. O., Teixeira, A. A., Lima, E. A., Batatinha, H. A., Gomes, L. M., Carvalho-Silva, M., . . Rosa Neto, J. C. (2014). Palmitoleic acid (n-7) attenuates the immunometabolic disturbances caused by a high-fat diet independently of PPARa. Mediators Inflamm, 2014, 582197. doi:10.1155/2014/582197

Stavrinou, P. S., Andreou, E., Aphamis, G., Pantzaris, M., loannou, M., Patrikios, I. S., \& Giannaki, C. D. (2020). The Effects of a 6-Month High Dose Omega-3 and Omega-6 Polyunsaturated Fatty Acids and Antioxidant Vitamins Supplementation on Cognitive Function and Functional Capacity in Older Adults with Mild Cognitive Impairment. Nutrients, 12(2). doi:10.3390/nu12020325

Tamer, F., Ulug, E., Akyol, A., \& Nergiz-Unal, R. (2020). The potential efficacy of dietary fatty acids and fructose induced inflammation and oxidative stress on the insulin signaling and fat accumulation in mice. Food Chem Toxicol, 135, 110914. doi:10.1016/j.fct.2019.110914

Wennberg, A. M. V., Hagen, C. E., Machulda, M. M., Knopman, D. S., Petersen, R. C., \& Mielke, M. M. (2019). The cross-sectional and longitudinal associations between IL-6, IL-10, and TNFa and cognitive outcomes in the mayo clinic study of aging. J Gerontol A Biol Sci Med Sci, 74(8), $1289-1295$.

doi:10.1093/gerona/gly217

Wu, J. H. Y., Marklund, M., Imamura, F., Tintle, N., Ardisson Korat, A. V., de Goede, J., . . Mozaffarian, D. (2017). Omega-6 fatty acid biomarkers and incident type 2 diabetes: pooled analysis of individual-level data for 39740 adults from 20 prospective cohort studies. Lancet Diabetes Endocrinol, 5(12), 965-974. doi:10.1016/s2213-8587(17)30307-8

Yu, H., Bi, Y., Ma, W., He, L., Yuan, L., Feng, J., \& Xiao, R. (2010). Long-term effects of high lipid and high energy diet on serum lipid, brain fatty acid composition, and memory and learning ability in mice. Int J Dev Neurosci, 28(3), 271-276. doi:10.1016/j.ijdevneu.2009.12.001

Zhang, D. A., Lam, V., Chu, V., \& Li, M. (2018). Type 2 diabetes with comorbid depression in relation to cognitive impairment: an opportunity for prevention? Mol Neurobiol, 55(1), 85-89. doi:10.1007/s12035-017-0719-8

Zheng, F., Yan, L., Yang, Z., Zhong, B., \& Xie, W. (2018). HbA(1c), diabetes and cognitive decline: the English longitudinal study of ageing. Diabetologia, 61(4), 839-848. doi:10.1007/s00125-017-4541-7

Zheng, M., Chang, B., Tian, L., Shan, C., Chen, H., Gao, Y., .. . Zhang, M. (2019). Relationship between inflammatory markers and mild cognitive impairment in Chinese patients with type 2 diabetes: a case-control study. BMC Endocr Disord, 19(1), 73. doi:10.1186/s12902-019-0402-3

\section{Tables}

Table 1. Multiple linear regression between adiposity and biochemistry biomarkers $(\mathrm{n}=372)$

\begin{tabular}{|c|c|c|c|c|c|c|c|c|c|c|}
\hline \multicolumn{2}{|l|}{ OGTT } & \multicolumn{2}{|c|}{ OGTT2 } & \multicolumn{2}{|c|}{ Insulin } & \multicolumn{2}{|c|}{ HOMA-IR } & \multicolumn{2}{|c|}{ QUICKI } & \\
\hline$\beta$ & $\mathrm{P}$ & $\beta$ & $\mathrm{P}$ & $\beta$ & $\mathbf{P}$ & $\beta$ & $\mathbf{P}$ & $\beta$ & P & \\
\hline BMI & -0.024 & 0.779 & -0.057 & 0.859 & 0.683 & $0.036 *$ & 0.011 & $0.001 * *$ & -0.003 & $0.003^{* *}$ \\
\hline Waist circumference & -0.003 & 0.821 & 0.014 & 0.469 & 0.149 & 0.106 & 0.004 & $0.003^{* *}$ & -0.001 & $0.001 * *$ \\
\hline Waist hip ratio & -0.518 & 0.759 & 6.552 & 0.258 & 13.182 & 0.360 & 0.387 & 0.090 & -0.137 & $0.041^{*}$ \\
\hline
\end{tabular}

Multiple linear regression adjusted for age, gender, energy, BMI, education, smoking habit, alcohol and energy intakes. OGTT, oral glucose tolerance test. HOMA-IR, homeostatic model assessment-insulin resistance. QUICKI, quantitative sensitivity check index. *Significant at $P<0.05$. **Significant at $P<0.01$.

Table 2. Multiple linear regression between adiposity and inflammation $(n=372)$ 


\begin{tabular}{lcccccccccccccc}
\hline \multicolumn{1}{c}{ IL-1 $\boldsymbol{\beta}$} & \multicolumn{1}{c}{$\boldsymbol{c}$ IL-10 } & \multicolumn{1}{c}{ NFkBp65 } & \multicolumn{2}{c}{ TNF- $\boldsymbol{\alpha}$} & \multicolumn{2}{c}{ hs-CRP } & \multicolumn{2}{c}{ CRP } & \multicolumn{2}{c}{ LPS } \\
\multicolumn{1}{c}{$\boldsymbol{\beta}$} & $\mathbf{P}$ & $\boldsymbol{\beta}$ & $\mathbf{P}$ & $\boldsymbol{\beta}$ & $\mathbf{P}$ & $\boldsymbol{\beta}$ & $\mathbf{P}$ & $\boldsymbol{\beta}$ & $\mathbf{P}$ & $\boldsymbol{\beta}$ & $\mathbf{P}$ & $\boldsymbol{\beta}$ & $\mathbf{P}$ \\
\hline BMI & 0.003 & 0.672 & -0.016 & 0.258 & 0.031 & 0.321 & -0.001 & 0.964 & 0.053 & $0.000^{* *}$ & 0.040 & $0.000^{* *}$ & -0.212 & 0.581 \\
Waist circumference & 0.000 & 0.844 & -0.001 & 0.931 & 0.008 & 0.448 & -0.001 & 0.895 & 0.017 & $0.001^{* *}$ & 0.013 & $0.004^{* *}$ & -0.136 & 0.660 \\
Waist hip ratio & 0.185 & 0.719 & -0.347 & 0.852 & 0.178 & 0.858 & -0.200 & 0.832 & 1.029 & 0.426 & 1.248 & 0.225 & 1.897 & 0.612 \\
\hline
\end{tabular}

Multiple linear regression adjusted for age, gender, energy, BMI, education, smoking habit, alcohol and energy intakes. IL, Interleukin. NFkBp65, nuclear factor kappa-B. TNF- $\alpha$, tumor necrosis factor- $\alpha$. hs-CRP, hypersensitive C-reactive protein. CRP, C-reactive protein. LPS, Lipopolysaccharide. *Significant at $P<0.05$. **Significant at $P<0.01$.

Table 3. Multiple linear regression between cognitive function score measured by MMSE and adiposity ( $\mathrm{n}=372$ )

\begin{tabular}{|c|c|c|c|c|c|c|c|c|c|c|c|c|}
\hline \multirow[t]{2}{*}{ MMSE } & & \multicolumn{2}{|c|}{ MMSE Orientation } & \multicolumn{2}{|c|}{ MMSE Computation } & \multicolumn{2}{|c|}{ MMSE Delayed recall } & \multicolumn{2}{|c|}{ MMSE Memory } & \multicolumn{2}{|c|}{ MMSE Language skill } & \multirow[b]{2}{*}{$\mathbf{P}$} \\
\hline & $\beta$ & $\mathbf{P}$ & $\beta$ & $\mathbf{P}$ & $\beta$ & $\mathbf{P}$ & $\beta$ & $\mathbf{P}$ & $\beta$ & $\mathbf{P}$ & $\beta$ & \\
\hline Waist circumference & -0.007 & 0.125 & -0.005 & 0.066 & -0.001 & 0.531 & -0.004 & 0.104 & -0.001 & 0.323 & -0.001 & 0.464 \\
\hline
\end{tabular}

Multiple linear regression adjusted for age, gender, energy, BMI, education, smoking habit, alcohol and energy intakes. MMSE, Minimental State Examination. *Significant at $P<0.05$. **Significant at $P<0.01$.

Table 4. Multiple linear regression between cognitive function score measured by MoCA and adiposity (n=372)

\begin{tabular}{|c|c|c|c|c|c|c|c|c|c|c|c|c|c|c|c|c|}
\hline \multirow[t]{2}{*}{ MoCA } & \multicolumn{3}{|c|}{ MoCA Naming } & \multicolumn{2}{|c|}{$\begin{array}{c}\text { MoCA } \\
\text { Orientation }\end{array}$} & \multicolumn{2}{|c|}{$\begin{array}{l}\text { MoCA Delayed } \\
\text { recall }\end{array}$} & \multicolumn{2}{|c|}{$\begin{array}{l}\text { MoCA Abstract } \\
\text { thinking }\end{array}$} & \multicolumn{2}{|c|}{$\begin{array}{c}\text { MoCA } \\
\text { Language skill }\end{array}$} & \multicolumn{2}{|c|}{$\begin{array}{l}\text { MoCA Visual } \\
\text { spatial ability }\end{array}$} & \multicolumn{2}{|c|}{$\begin{array}{c}\text { MoCA } \\
\text { Attention }\end{array}$} & \multirow[b]{2}{*}{$\mathbf{P}$} \\
\hline & $\beta$ & $\mathrm{P}$ & $\beta$ & $\mathbf{P}$ & $\beta$ & $\mathbf{P}$ & $\beta$ & $\mathbf{P}$ & $\beta$ & $\mathbf{P}$ & $\beta$ & P & $\beta$ & $\mathbf{P}$ & $\beta$ & \\
\hline BMI & -0.033 & 0.154 & 0.005 & 0.329 & -0.008 & 0.179 & -0.015 & 0.274 & 0.002 & 0.900 & -0.022 & $0.049 *$ & 0.010 & 0.912 & -0.004 & 0.449 \\
\hline $\begin{array}{l}\text { Waist } \\
\text { circumference }\end{array}$ & -0.013 & 0.090 & 0.001 & 0.493 & -0.002 & 0.208 & -0.004 & 0.194 & 0.004 & 0.457 & -0.009 & $0.026^{*}$ & -0.001 & 0.515 & -0.002 & 0.226 \\
\hline Waist hip ratio & 1.726 & 0.830 & 0.030 & 0.860 & -0.609 & 0.157 & 0.707 & 0.869 & 0.846 & 0.183 & -0.308 & 0.611 & 1.788 & 0.199 & -0.872 & 0.183 \\
\hline
\end{tabular}

Multiple linear regression adjusted for age, gender, energy, BMI, education, smoking habit, alcohol and energy intakes. MoCA, Montreal Cognitive Assessment. *Significant at $P<0.05$. **Significant at $P<0.01$.

Table 5. Multiple linear regression between plasma fatty acids (\%) and biochemistry biomarkers $(\mathrm{n}=372)$

\begin{tabular}{|c|c|c|c|c|c|c|c|c|c|c|}
\hline \multicolumn{2}{|c|}{ OGTT } & \multicolumn{2}{|c|}{ OGTT2 } & \multicolumn{2}{|c|}{ Insulin } & \multicolumn{2}{|c|}{ HOMA-IR } & \multicolumn{2}{|c|}{ QUICKI } & \multirow[b]{2}{*}{$\mathbf{P}$} \\
\hline & $\beta$ & $\mathbf{P}$ & $\beta$ & $\mathbf{P}$ & $\beta$ & $\mathbf{P}$ & $\beta$ & $\mathbf{P}$ & B & \\
\hline SFAs & -0.015 & 0.862 & -0.102 & 0.249 & 0.099 & 0.980 & 0.002 & 0.810 & 0.000 & 0.903 \\
\hline C14:0 & 2.387 & $0.011 *$ & 2.107 & $0.041 *$ & -3.189 & 0.833 & 0.183 & $0.007^{* *}$ & -0.069 & $0.000 * *$ \\
\hline C15:0 & 1.266 & 0.724 & 4.655 & 0.720 & -24.863 & 0.445 & -0.328 & 0.377 & 0.036 & 0.686 \\
\hline C16:0 & 0.061 & 0.395 & -0.085 & 0.181 & 0.609 & 0.358 & 0.014 & $0.020 *$ & -0.004 & $0.036 *$ \\
\hline C17:0 & 3.012 & 0.378 & 11.447 & 0.296 & -83.194 & $0.010 *$ & -0.231 & 0.325 & -0.096 & 0.463 \\
\hline C18:0 & -0.073 & 0.186 & -0.165 & $0.036^{*}$ & 0.483 & 0.359 & 0.008 & 0.189 & -0.002 & 0.396 \\
\hline MUFAs & 0.174 & $0.010 *$ & 0.279 & $0.009 * *$ & -0.631 & 0.647 & 0.000 & 0.253 & -0.001 & 0.123 \\
\hline C16:1 & 0.387 & 0.353 & -0.143 & 0.918 & -2.079 & 0.646 & 0.022 & 0.245 & -0.009 & 0.155 \\
\hline C18:1n-9c & 0.174 & $0.010^{*}$ & 0.279 & $0.009 * *$ & -0.631 & 0.647 & 0.000 & 0.253 & -0.001 & 0.123 \\
\hline PUFAs & -0.087 & 0.139 & -0.013 & 0.345 & -0.087 & 0.568 & -0.010 & $0.008^{* *}$ & 0.003 & $0.001^{* *}$ \\
\hline n-3 PUFA & -0.282 & 0.396 & 0.399 & 0.304 & -0.440 & 0.851 & -0.019 & 0.389 & 0.007 & 0.326 \\
\hline C18:3n-3 & 1.564 & $0.031 *$ & 3.696 & $0.002^{* *}$ & -2.626 & 0.545 & 0.023 & 0.587 & -0.017 & 0.237 \\
\hline$C 20: 5 n-3$ & -0.425 & 0.743 & 1.594 & 0.159 & -5.509 & 0.532 & -0.013 & 0.788 & -0.002 & 0.977 \\
\hline$C 22: 6 n-3$ & -0.527 & 0.081 & 0.266 & 0.400 & -0.736 & 0.541 & -0.042 & 0.079 & 0.014 & $0.037^{*}$ \\
\hline n-6 PUFAs & -0.069 & 0.222 & -0.012 & 0.542 & -0.024 & 0.549 & -0.009 & $0.006^{* *}$ & 0.003 & $0.000 * *$ \\
\hline C18:2n-6c & -0.018 & 0.683 & 0.007 & 0.998 & -0.338 & 0.245 & -0.011 & $0.000^{* *}$ & 0.003 & $0.001 * *$ \\
\hline C18:3n-6 & -2.195 & 0.181 & -1.721 & 0.991 & 3.449 & 0.373 & -0.017 & 0.656 & 0.011 & 0.953 \\
\hline$C 20: 3 n-6$ & -0.982 & 0.139 & -1.410 & 0.675 & 0.618 & 0.810 & 0.021 & 0.335 & -0.002 & 0.433 \\
\hline C20:4n-6 & -0.171 & $0.045^{*}$ & -0.121 & 0.826 & 0.709 & 0.400 & 0.001 & 0.889 & 0.000 & 0.977 \\
\hline SCD-16 & 9.091 & 0.467 & -2.213 & 0.694 & -72.070 & 0.554 & 0.160 & 0.436 & -0.117 & 0.287 \\
\hline SCD-18 & 0.847 & $0.008^{* *}$ & 1.442 & $0.004^{* *}$ & -2.278 & 0.605 & -0.006 & 0.641 & -0.003 & 0.353 \\
\hline D6D & -45.842 & 0.275 & -42.343 & 0.914 & 138.495 & 0.256 & 1.921 & 0.207 & -0.375 & 0.310 \\
\hline D5D & 0.031 & 0.607 & 0.081 & 0.430 & 0.098 & 0.949 & 0.000 & 0.425 & 0.000 & 0.582 \\
\hline
\end{tabular}

Multiple linear regression adjusted for age, gender, energy, BMI, education, smoking habit, alcohol and energy intakes. SFAs, saturated fatty acids. MUFAs, monounsaturated fatty acids. PUFAs, polyunsaturated fatty acids. SCD: stearoyl-CoA desaturase; D5D: delta-5desaturase; D6D: delta-6-desaturase. OGTT, oral glucose tolerance test. HOMA-IR, homeostatic model assessment-insulin resistance. QUICKI, quantitative sensitivity check index. *Significant at $P<0.05$. **Significant at $P<0.01$.

Table 6. Multiple linear regression between plasma fatty acids (\%) and inflammation $(n=372)$ 


\begin{tabular}{|c|c|c|c|c|c|c|c|c|c|c|c|c|c|c|}
\hline & \multicolumn{2}{|c|}{ IL-1 $\beta$} & \multicolumn{2}{|c|}{ IL-10 } & \multicolumn{2}{|c|}{ NFKBp65 } & \multicolumn{2}{|c|}{ TNF- $\alpha$} & \multicolumn{2}{|c|}{ hs-CRP } & \multicolumn{2}{|c|}{ CRP } & \multicolumn{2}{|c|}{ LPS } \\
\hline & $\beta$ & $\mathbf{P}$ & $\beta$ & $\mathbf{P}$ & $\beta$ & $P$ & $\beta$ & $\mathbf{P}$ & $\beta$ & P & $\beta$ & P & $\beta$ & $\mathrm{P}$ \\
\hline SFAs & -0.002 & 0.857 & 0.020 & 0.207 & 0.051 & 0.186 & 0.015 & 0.370 & -0.016 & 0.073 & -0.014 & 0.150 & 1.136 & $0.043^{3}$ \\
\hline C14:0 & -0.316 & 0.152 & 0.180 & 0.822 & 0.325 & 0.514 & -0.020 & 0.991 & -0.059 & 0.226 & -0.121 & 0.443 & -5.514 & 0.318 \\
\hline C15:0 & -0.571 & 0.520 & -0.334 & 0.810 & 3.774 & 0.326 & -0.587 & 0.851 & -0.248 & 0.575 & 0.274 & 0.958 & -52.829 & 0.433 \\
\hline C16:0 & -0.017 & 0.230 & 0.058 & $0.004^{* *}$ & 0.002 & 0.700 & -0.003 & 0.881 & -0.003 & 0.847 & 0.000 & 0.966 & 1.461 & $0.014^{\prime}$ \\
\hline C17:0 & -0.174 & 0.629 & 0.448 & 0.853 & 4.309 & 0.131 & 1.476 & 0.198 & -1.742 & $0.007 * *$ & -1.846 & $0.005^{* *}$ & 31.483 & 0.218 \\
\hline C18:0 & -0.007 & 0.503 & 0.040 & $0.012 *$ & 0.034 & 0.298 & 0.002 & 0.759 & -0.019 & $0.019 *$ & -0.020 & $0.020^{*}$ & 1.686 & $0.000^{\prime}$ \\
\hline MUFAs & 0.011 & 0.342 & 0.003 & 0.870 & 0.037 & 0.488 & 0.019 & 0.384 & 0.017 & $0.016^{*}$ & 0.008 & 0.109 & -1.070 & 0.064 \\
\hline C16:1 & -0.117 & 0.179 & -0.043 & 0.664 & -0.090 & 0.742 & 0.017 & 0.870 & 0.040 & $0.046^{*}$ & 0.052 & 0.065 & -5.025 & $0.025^{\prime}$ \\
\hline $\begin{array}{l}\text { C18:1n- } \\
\text { 9c }\end{array}$ & 0.011 & 0.342 & 0.003 & 0.870 & 0.037 & 0.488 & 0.019 & 0.384 & 0.017 & $0.016^{*}$ & 0.008 & 0.109 & -1.070 & 0.064 \\
\hline PUFAs & 0.011 & 0.447 & -0.034 & 0.071 & -0.008 & 0.654 & -0.011 & 0.475 & -0.003 & 0.590 & 0.012 & 0.534 & -0.547 & 0.206 \\
\hline $\begin{array}{l}\text { n-3 } \\
\text { PUFA }\end{array}$ & -0.038 & 0.314 & -0.005 & 0.907 & -0.181 & 0.303 & -0.165 & $0.028 *$ & -0.117 & $0.034 *$ & -0.088 & 0.078 & -3.916 & 0.116 \\
\hline $\begin{array}{l}\text { C18:3n- } \\
3\end{array}$ & -0.073 & 0.543 & -0.385 & $0.042^{*}$ & -0.270 & 0.569 & -0.218 & 0.272 & -0.114 & 0.993 & -0.100 & 0.858 & -16.313 & $0.007^{>}$ \\
\hline $\begin{array}{l}\text { C20:5n- } \\
3\end{array}$ & -0.075 & 0.611 & -0.198 & 0.718 & -0.725 & 0.366 & -0.359 & 0.241 & -0.545 & $0.009 * *$ & -0.391 & $0.033^{*}$ & -17.344 & 0.119 \\
\hline $\begin{array}{l}\text { C22:6n- } \\
3\end{array}$ & -0.049 & 0.325 & 0.012 & 0.941 & -0.185 & 0.378 & -0.099 & 0.233 & -0.075 & 0.385 & -0.049 & 0.564 & -0.610 & 0.817 \\
\hline $\begin{array}{l}\text { n-6 } \\
\text { PUFAs }\end{array}$ & 0.011 & 0.375 & -0.036 & $0.037^{*}$ & -0.016 & 0.598 & -0.006 & 0.732 & 0.003 & 0.631 & 0.009 & 0.778 & -0.392 & 0.407 \\
\hline $\begin{array}{l}\text { C18:2n- } \\
6 c\end{array}$ & 0.005 & 0.753 & -0.033 & $0.005^{* *}$ & -0.019 & 0.252 & -0.013 & 0.161 & 0.004 & 0.618 & 0.005 & 0.839 & -0.734 & $0.049^{\prime}$ \\
\hline $\begin{array}{l}\text { C18:3n- } \\
6\end{array}$ & -0.290 & 0.548 & -0.902 & $0.044^{*}$ & -1.085 & 0.510 & 0.189 & 0.648 & -0.377 & 0.970 & -0.016 & 0.346 & -14.444 & 0.201 \\
\hline $\begin{array}{l}\text { C20:3n- } \\
6\end{array}$ & -0.189 & 0.200 & -0.261 & 0.069 & -0.153 & 0.986 & -0.059 & 0.739 & 0.036 & 0.065 & -0.099 & 0.356 & -1.580 & 0.413 \\
\hline $\begin{array}{l}\mathrm{C} 20: 4 n- \\
6\end{array}$ & 0.024 & 0.127 & -0.032 & 0.259 & -0.059 & 0.518 & 0.034 & 0.169 & 0.014 & 0.359 & 0.024 & 0.139 & -0.824 & 0.265 \\
\hline SCD-16 & -2.884 & 0.294 & -2.363 & 0.415 & -0.403 & 0.958 & 0.974 & 0.770 & 1.572 & $0.020 *$ & 1.695 & $0.038 *$ & -188.223 & $0.006^{\prime}$ \\
\hline SCD-18 & 0.069 & 0.282 & -0.091 & 0.367 & 0.112 & 0.752 & 0.019 & 0.900 & 0.117 & $0.012 *$ & 0.083 & 0.054 & -9.615 & $0.001^{\prime}$ \\
\hline D6D & -9.942 & 0.449 & -16.988 & 0.172 & -32.305 & 0.464 & 8.422 & 0.515 & -10.779 & 0.993 & -2.775 & 0.483 & -346.911 & 0.277 \\
\hline D5D & 0.015 & 0.199 & -0.004 & 0.982 & -0.006 & 0.685 & 0.010 & 0.512 & 0.000 & 0.211 & 0.012 & 0.881 & -0.138 & 0.979 \\
\hline
\end{tabular}

Multiple linear regression adjusted for age, gender, energy, BMI, education, smoking habit, alcohol and energy intakes. SFAs, saturated fatty acids. MUFAs, monounsaturated fatty acids. PUFAs, polyunsaturated fatty acids. IL, Interleukin. NFkBp65, nuclear factor kappa-B. TNF- $\alpha$, tumor necrosis factor- $\alpha$. hs-CRP, hypersensitive C-reactive protein. CRP, C-reactive protein. LPS, Lipopolysaccharide. *Significant at $P<0.05$. **Significant at $P<0.01$.

Table 7. Multiple linear regression between plasma fatty acids (\%) and cognitive function score measured by MMSE ( $\mathrm{n}=372$ )

\begin{tabular}{|c|c|c|c|c|c|c|c|c|c|c|c|c|}
\hline & \multicolumn{2}{|c|}{ MMSE } & \multicolumn{2}{|c|}{ MMSE Orientation } & \multicolumn{2}{|c|}{ MMSE Computation } & \multicolumn{2}{|c|}{ MMSE Memory } & \multicolumn{2}{|c|}{ MMSE Delayed recall } & \multicolumn{2}{|c|}{ MMSE Language skill } \\
\hline & $\beta$ & $\mathrm{P}$ & $\beta$ & $\mathrm{P}$ & $\beta$ & $\mathrm{P}$ & $\beta$ & $\mathrm{P}$ & $\beta$ & $\mathrm{P}$ & $\beta$ & $\mathrm{P}$ \\
\hline SFAs & -0.064 & $0.002 * *$ & -0.019 & $0.010^{*}$ & -0.014 & 0.271 & 0.001 & 0.751 & -0.026 & 0.005 & -0.018 & 0.059 \\
\hline C14:0 & -0.885 & 0.161 & -0.085 & 0.568 & -0.350 & 0.383 & 0.013 & 0.860 & -0.234 & 0.443 & -0.260 & 0.255 \\
\hline C15:0 & 1.991 & 0.506 & 0.603 & 0.435 & -1.319 & 0.473 & 0.069 & 0.908 & 2.604 & $0.028 *$ & 0.957 & 0.503 \\
\hline C16:0 & -0.057 & 0.107 & -0.035 & $0.018^{*}$ & 0.008 & 0.870 & 0.001 & 0.933 & -0.026 & 0.106 & -0.015 & 0.271 \\
\hline C17:0 & 0.194 & 0.371 & 0.894 & 0.125 & 0.582 & 0.492 & -0.080 & 0.807 & -0.346 & 0.845 & -0.790 & 0.991 \\
\hline C18:0 & -0.052 & $0.014 *$ & -0.028 & $0.008^{* *}$ & -0.008 & 0.385 & 0.002 & 0.675 & -0.022 & $0.025^{*}$ & -0.003 & 0.372 \\
\hline MUFAs & 0.015 & 0.299 & 0.021 & 0.096 & 0.012 & 0.438 & -0.003 & 0.386 & 0.001 & 0.627 & -0.005 & 0.778 \\
\hline C16:1 & -0.309 & 0.137 & 0.031 & 0.738 & -0.116 & 0.430 & -0.007 & 0.754 & -0.044 & 0.614 & -0.141 & 0.054 \\
\hline C18:1n-9c & 0.015 & 0.299 & 0.021 & 0.096 & 0.012 & 0.438 & -0.003 & 0.386 & 0.001 & 0.627 & -0.005 & 0.778 \\
\hline PUFAs & 0.057 & 0.082 & 0.013 & 0.140 & 0.012 & 0.626 & 0.001 & 0.763 & 0.024 & 0.072 & 0.014 & 0.431 \\
\hline n-3 PUFA & 0.154 & 0.094 & -0.031 & 0.967 & 0.088 & 0.204 & -0.004 & 0.936 & 0.079 & 0.106 & 0.037 & 0.308 \\
\hline C18:3n-3 & -0.061 & 0.550 & 0.026 & 0.735 & 0.132 & 0.372 & -0.035 & 0.454 & -0.020 & 0.609 & -0.200 & 0.546 \\
\hline$C 20: 5 n-3$ & 0.194 & 0.827 & -0.054 & 0.920 & 0.203 & 0.674 & -0.008 & 0.932 & 0.133 & 0.821 & -0.117 & 0.617 \\
\hline$C 22: 6 n-3$ & 0.040 & 0.347 & -0.041 & 0.732 & 0.050 & 0.417 & 0.000 & 0.844 & 0.008 & 0.507 & 0.029 & 0.355 \\
\hline n-6 PUFAs & 0.050 & 0.148 & 0.012 & 0.156 & 0.004 & 0.904 & 0.001 & 0.708 & 0.023 & 0.101 & 0.014 & 0.382 \\
\hline$C 18: 2 n-6 c$ & 0.030 & 0.066 & 0.010 & 0.157 & -0.011 & 0.627 & 0.000 & 0.737 & 0.025 & $0.004^{* *}$ & 0.008 & 0.182 \\
\hline C18:3n-6 & -0.410 & 0.118 & 0.541 & 0.471 & -0.493 & 0.155 & 0.047 & 0.673 & -0.410 & 0.087 & -0.189 & 0.192 \\
\hline$C 20: 3 n-6$ & 0.128 & 0.584 & 0.198 & 0.569 & -0.349 & 0.085 & -0.008 & 0.910 & 0.126 & 0.646 & 0.219 & 0.586 \\
\hline$C 20: 4 n-6$ & 0.089 & 0.373 & 0.042 & 0.084 & 0.049 & 0.218 & 0.000 & 0.949 & -0.017 & 0.218 & 0.018 & 0.835 \\
\hline SCD-16 & -7.385 & 0.224 & 1.824 & 0.471 & -4.110 & 0.331 & -0.226 & 0.745 & -0.119 & 0.971 & -3.488 & 0.092 \\
\hline SCD-18 & 0.266 & $0.033^{*}$ & 0.118 & $0.038^{*}$ & 0.124 & 0.163 & -0.004 & 0.772 & 0.049 & 0.256 & 0.031 & 0.339 \\
\hline D6D & -20.981 & 0.056 & 14.523 & 0.593 & -7.201 & 0.324 & 0.715 & 0.762 & -20.253 & $0.010^{*}$ & -12.021 & 0.065 \\
\hline D5D & 0.022 & 0.362 & 0.002 & 0.506 & 0.041 & $0.032 *$ & -0.001 & 0.847 & -0.010 & 0.454 & -0.013 & 0.426 \\
\hline
\end{tabular}

Multiple linear regression adjusted for age, gender, energy, BMI, education, smoking habit, alcohol and energy intakes. SFA, saturated fatty acids. MUFA, monounsaturated fatty acids. PUFA, polyunsaturated fatty acids. SCD: stearoyl-CoA desaturase; D5D: delta-5desaturase; D6D: delta-6-desaturase. MMSE, Mini-mental State Examination. *Significant at $P<0.05 .{ }^{* *}$ Significant at $P<0.01$.

Table 8. Multiple linear regression between plasma fatty acids (\%) and cognitive function score measured by MoCA ( $\mathrm{n}=372$ ) 


\begin{tabular}{|c|c|c|c|c|c|c|c|c|c|c|c|c|c|c|}
\hline & \multicolumn{2}{|c|}{ MoCA } & \multicolumn{2}{|c|}{ MoCA Naming } & \multicolumn{2}{|c|}{ MoCA Orientation } & \multicolumn{2}{|c|}{$\begin{array}{l}\text { MoCA Delayed } \\
\text { recall }\end{array}$} & \multicolumn{2}{|c|}{$\begin{array}{l}\text { MoCA Abstract } \\
\text { thinking }\end{array}$} & \multicolumn{2}{|c|}{$\begin{array}{l}\text { MoCA Language } \\
\text { skill }\end{array}$} & \multicolumn{2}{|c|}{$\begin{array}{l}\text { MoCA Visual } \\
\text { spatial ability }\end{array}$} \\
\hline & $\beta$ & $\mathrm{P}$ & $\beta$ & $\mathrm{P}$ & $\beta$ & $\mathrm{P}$ & $\beta$ & $\mathrm{P}$ & $\beta$ & P & $\beta$ & P & $\beta$ & P \\
\hline SFAs & -0.039 & 0.146 & 0.002 & 0.297 & -0.013 & $0.031 *$ & 0.014 & 0.682 & 0.011 & 0.769 & -0.037 & $0.003 * *$ & -0.009 & 0.294 \\
\hline C14:0 & -0.375 & 0.554 & 0.010 & 0.704 & -0.166 & 0.324 & 0.257 & 0.667 & -0.277 & 0.193 & -0.480 & 0.083 & 0.323 & 0.460 \\
\hline C15:0 & 1.309 & 0.811 & 0.154 & 0.643 & 0.724 & 0.338 & -0.620 & 0.857 & -0.523 & 0.787 & -1.022 & 0.660 & 1.722 & 0.570 \\
\hline C16:0 & 0.002 & 0.840 & 0.002 & 0.481 & -0.032 & $0.003 * *$ & 0.030 & 0.360 & 0.017 & 0.309 & -0.044 & $0.020 *$ & 0.033 & 0.405 \\
\hline C17:0 & 0.443 & 0.394 & -0.198 & 0.402 & -0.061 & 0.850 & 2.815 & 0.061 & -1.048 & 0.590 & 0.366 & 0.508 & -0.169 & 0.765 \\
\hline C18:0 & -0.075 & $0.030 *$ & -0.002 & 0.596 & -0.022 & $0.004 * *$ & -0.004 & 0.585 & 0.012 & 0.634 & -0.052 & $0.000^{* *}$ & -0.002 & 0.379 \\
\hline MUFAs & 0.126 & $0.020 *$ & 0.003 & 0.456 & 0.016 & 0.090 & 0.066 & $0.034^{*}$ & -0.007 & 0.802 & 0.034 & 0.100 & 0.023 & 0.138 \\
\hline C16:1 & -0.118 & 0.662 & -0.015 & 0.752 & 0.001 & 0.934 & -0.060 & 0.640 & -0.154 & $0.036 *$ & 0.053 & 0.771 & 0.052 & 0.564 \\
\hline $\begin{array}{l}\text { C18:1n- } \\
\text { 9c }\end{array}$ & 0.126 & $0.020 *$ & 0.003 & 0.456 & 0.016 & 0.090 & 0.066 & $0.034^{*}$ & -0.007 & 0.802 & 0.034 & 0.100 & 0.023 & 0.138 \\
\hline PUFAs & 0.005 & 0.970 & -0.002 & 0.250 & 0.016 & $0.028 *$ & 0.003 & 0.885 & -0.012 & 0.279 & 0.011 & 0.553 & -0.007 & 0.773 \\
\hline $\begin{array}{l}\text { n-3 } \\
\text { PUFA }\end{array}$ & 0.049 & 0.486 & 0.007 & 0.655 & -0.067 & 0.293 & 0.050 & 0.448 & -0.071 & 0.320 & 0.068 & 0.171 & 0.017 & 0.675 \\
\hline $\begin{array}{l}\text { C18:3n- } \\
3\end{array}$ & -1.012 & 0.609 & -0.086 & $0.011 *$ & 0.032 & 0.612 & -0.364 & 0.593 & -0.100 & 0.870 & -0.015 & 0.772 & -0.598 & 0.153 \\
\hline $\begin{array}{l}\mathrm{C} 20: 5 n- \\
3\end{array}$ & 0.290 & 0.871 & 0.050 & 0.389 & -0.068 & 0.865 & -0.210 & 0.627 & -0.105 & 0.581 & 0.275 & 0.251 & 0.298 & 0.599 \\
\hline $\begin{array}{l}\text { C22:6n- } \\
3\end{array}$ & -0.045 & 0.571 & 0.025 & 0.276 & -0.085 & 0.162 & 0.091 & 0.233 & -0.072 & 0.334 & 0.083 & 0.129 & -0.056 & 0.995 \\
\hline $\begin{array}{l}\text { n-6 } \\
\text { PUFAs }\end{array}$ & 0.007 & 0.960 & 0.000 & 0.747 & 0.014 & 0.056 & 0.001 & 0.976 & -0.005 & 0.590 & 0.012 & 0.488 & -0.010 & 0.581 \\
\hline $\begin{array}{l}\text { C18:2n- } \\
6 c\end{array}$ & -0.019 & 0.742 & -0.001 & 0.559 & 0.012 & $0.040 *$ & -0.031 & 0.225 & -0.004 & 0.946 & 0.024 & $0.010 *$ & -0.020 & 0.456 \\
\hline $\begin{array}{l}\text { C18:3n- } \\
6\end{array}$ & 0.306 & 0.249 & -0.016 & 0.881 & 0.128 & 0.906 & 0.290 & 0.761 & -0.927 & $0.001 * *$ & 0.842 & 0.482 & 0.097 & 0.525 \\
\hline $\begin{array}{l}\text { C20:3n- } \\
6\end{array}$ & -0.207 & 0.112 & -0.059 & $0.028^{*}$ & 0.144 & 0.517 & -0.133 & 0.380 & -0.288 & $0.003^{* *}$ & 0.047 & 0.571 & 0.083 & 0.770 \\
\hline $\begin{array}{l}\mathrm{C} 20: 4 n- \\
6\end{array}$ & 0.115 & 0.673 & -0.005 & 0.514 & 0.036 & 0.050 & -0.001 & 0.703 & 0.011 & 0.819 & 0.027 & 0.554 & 0.003 & 0.797 \\
\hline SCD-16 & -3.830 & 0.606 & -0.563 & 0.639 & 0.752 & 0.612 & -1.721 & 0.625 & -5.411 & $0.012 *$ & 2.370 & 0.597 & 0.978 & 0.650 \\
\hline SCD-18 & 0.718 & $0.005^{* *}$ & 0.018 & 0.365 & 0.072 & 0.069 & 0.268 & $0.047 *$ & -0.061 & 0.918 & 0.272 & $0.004^{* *}$ & 0.129 & 0.112 \\
\hline D6D & 18.230 & 0.367 & -0.478 & 0.924 & 3.491 & 0.796 & 6.005 & 0.694 & -21.470 & $0.004 * *$ & 22.931 & 0.440 & 6.714 & 0.749 \\
\hline D5D & 0.045 & 0.203 & 0.004 & 0.105 & 0.008 & 0.214 & -0.004 & 0.984 & 0.023 & $0.037 *$ & 0.015 & 0.182 & -0.008 & 0.868 \\
\hline
\end{tabular}

Multiple linear regression adjusted for age, gender, energy, BMI, education, smoking habit, alcohol and energy intakes. SFAs, saturated fatty acids. MUFAs, monounsaturated fatty acids. PUFAs, polyunsaturated fatty acids. SCD: stearoyl-CoA desaturase; D5D: delta-5desaturase; D6D: delta-6-desaturase. MoCA, Montreal Cognitive Assessment. *Significant at $P<0.05$. **Significant at $P<0.01$.

Table9. Multiple linear regression between cognitive function score measured by MMSE, inflammation and biochemistry biomarkers $(\mathrm{n}=372)$

\begin{tabular}{|c|c|c|c|c|c|c|c|c|c|c|c|c|}
\hline & \multicolumn{2}{|c|}{ MMSE } & \multicolumn{2}{|c|}{ MMSE Orientation } & \multicolumn{2}{|c|}{ MMSE Computation } & \multicolumn{2}{|c|}{ MMSE Memory } & \multicolumn{2}{|c|}{ MMSE Delayed recall } & \multicolumn{2}{|c|}{ MMSE Language skill } \\
\hline & $\beta$ & $\mathbf{P}$ & $\beta$ & $\mathbf{P}$ & $\beta$ & P & $\beta$ & $\mathbf{P}$ & $\beta$ & $\mathbf{P}$ & $\beta$ & $\mathbf{P}$ \\
\hline IL-1 $\beta$ & -0.423 & $0.008 * *$ & -0.166 & $0.007 * *$ & -0.047 & 0.561 & 0.009 & 0.598 & -0.177 & $0.007 * *$ & -0.058 & 0.274 \\
\hline IL-10 & 0.010 & 0.940 & -0.005 & 0.836 & 0.102 & 0.236 & 0.002 & 0.918 & -0.072 & 0.121 & -0.037 & 0.534 \\
\hline NFкBp65 & -0.124 & $0.002 * *$ & -0.026 & 0.070 & -0.066 & $0.012^{*}$ & 0.004 & 0.496 & -0.038 & $0.027 *$ & 0.001 & 0.728 \\
\hline TNF- $\alpha$ & -0.061 & 0.493 & 0.021 & 0.568 & -0.029 & 0.607 & -0.004 & 0.738 & -0.024 & 0.601 & -0.055 & 0.252 \\
\hline hs-CRP & 0.188 & 0.405 & 0.012 & 0.689 & -0.008 & 0.995 & -0.006 & 0.744 & 0.122 & 0.063 & 0.099 & 0.316 \\
\hline CRP & 0.142 & 0.738 & 0.015 & 0.672 & 0.036 & 0.714 & -0.001 & 0.952 & 0.071 & 0.378 & 0.058 & 0.832 \\
\hline LPS & 0.000 & 0.873 & 0.000 & 0.825 & 0.000 & 0.892 & 0.000 & 0.841 & -0.002 & 0.224 & 0.001 & 0.258 \\
\hline OGTT & 0.007 & 0.928 & -0.010 & 0.565 & 0.024 & 0.392 & -0.006 & 0.118 & -0.007 & 0.663 & 0.002 & 0.921 \\
\hline OGTT2 & 0.016 & 0.607 & -0.003 & 0.420 & 0.011 & 0.791 & -0.001 & 0.764 & 0.002 & 0.565 & 0.008 & 0.856 \\
\hline Insulin & -0.004 & 0.105 & -0.002 & 0.054 & 0.000 & 0.810 & 0.000 & 0.945 & -0.002 & 0.088 & 0.000 & 0.744 \\
\hline HOMA-IR & 0.035 & 0.651 & -0.019 & 0.510 & 0.312 & 0.396 & -0.012 & 0.621 & -0.308 & 0.046 & 0.080 & 0.823 \\
\hline QUICKI & -1.555 & 0.668 & -0.962 & 0.311 & -1.489 & 0.214 & 0.096 & 0.489 & 1.126 & 0.055 & -0.301 & 0.792 \\
\hline
\end{tabular}

Multiple linear regression adjusted for age, gender, energy, BMI, education, smoking habit, alcohol and energy intakes. IL, Interleukin. NFkBp65, nuclear factor kappa-B. TNF- $\alpha$, tumor necrosis factor- $\alpha$. hs-CRP, hypersensitive C-reactive protein. CRP, C-reactive protein. OGTT, oral glucose tolerance test. HOMA-IR, homeostatic model assessment-insulin resistance. QUICKI, quantitative sensitivity check index. LPS, Lipopolysaccharide. MMSE, Mini-mental State Examination. *Significant at $P<0.05$. **Significant at $P<0.01$.

Table10. Multiple linear regression between cognitive function score measured by MoCA, inflammation and biochemistry biomarkers $(n=372)$ 


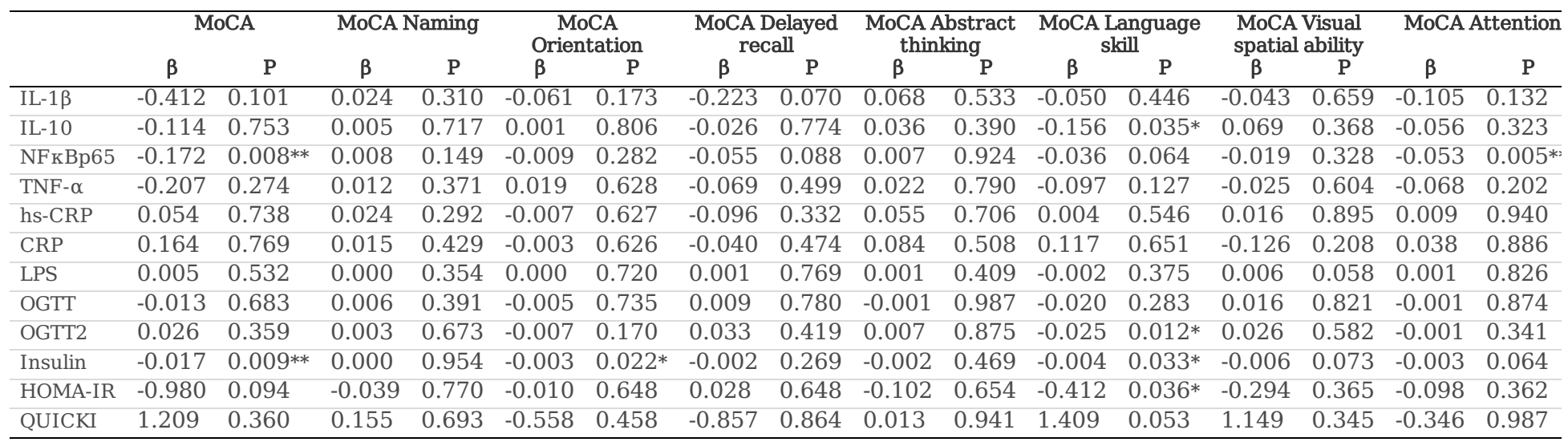

Multiple linear regression adjusted for age, gender, energy, BMI, education, smoking habit, alcohol and energy intakes. IL, Interleukin. NFkBp65, nuclear factor kappa-B. TNF- $\alpha$, tumor necrosis factor- $\alpha$. hs-CRP, hypersensitive C-reactive protein. CRP, C-reactive protein. OGTT, oral glucose tolerance test. HOMA-IR, homeostatic model assessment-insulin resistance. QUICKI, quantitative sensitivity check index. LPS, Lipopolysaccharide. MoCA, Montreal Cognitive Assessment. *Significant at $P<0.05$. **Significant at $P<0.01$.

Table 11. Summary of mediation models when mediator is IL-10

\begin{tabular}{|c|c|c|c|c|c|c|c|c|}
\hline $\begin{array}{l}\text { Independent } \\
\text { variable }\end{array}$ & Mediator & $\begin{array}{c}\text { Dependent } \\
\text { variable }\end{array}$ & $\begin{array}{l}\text { Direct } \\
\text { effects }\end{array}$ & $\mathrm{P}$ & $\begin{array}{l}\text { Indirect } \\
\text { effects }\end{array}$ & $P$ & Total effects & $\mathbf{P}$ \\
\hline C16:0 & IL10 & MoCA Language skill & -0.033 & 0.115 & -0.007 & 0.142 & -0.04 & 0.053 \\
\hline C18:0 & & & -0.046 & 0.007 & -0.005 & 0.182 & -0.05 & 0.003 \\
\hline C18:2n-6c & & & 0.024 & 0.054 & 0.003 & 0.168 & 0.027 & 0.029 \\
\hline
\end{tabular}

Simple mediation analysis adjusted for age, gender, energy intakes, BMI, education, smoking and drinking habits. IL, Interleukin. MoCA, Montreal Cognitive Assessment. *Significant at $P<0.05$. **Significant at $P<0.01$.

Table 12. Summary of mediation models when mediator is HOMA-IR

\begin{tabular}{lcccccccc}
\hline $\begin{array}{l}\text { Independent } \\
\text { variable }\end{array}$ & Mediator & $\begin{array}{c}\text { Dependent } \\
\text { variable }\end{array}$ & $\begin{array}{c}\text { Direct } \\
\text { effects }\end{array}$ & $\mathbf{P}$ & $\begin{array}{c}\text { Indirect } \\
\text { effects }\end{array}$ & $\mathbf{P}$ & Total effects & P \\
\hline C16:0 & HOMA-IR & MoCA Language skill & -0.035 & 0.096 & -0.005 & 0.28 & -0.04 & 0.053 \\
C18:2n-6c & & & 0.024 & 0.052 & 0.003 & 0.296 & 0.027 & 0.027 \\
\hline
\end{tabular}

Simple mediation analysis adjusted for age, gender, energy intakes, BMI, education, smoking and drinking habits. HOMA-IR, homeostatic model assessment-insulin resistance. MoCA, Montreal Cognitive Assessment. *Significant at $P<0.05$. **Significant at $P<0.01$. 